\title{
Polyurethane paint adhesion improvement on aluminium alloy treated by plasma jet and dielectric barrier discharge
}

\author{
T.S.M. Mui, L.L.G. Silva, V. Prysiazhnyi \& K.G. Kostov
}

To cite this article: T.S.M. Mui, L.L.G. Silva, V. Prysiazhnyi \& K.G. Kostov (2016) Polyurethane paint adhesion improvement on aluminium alloy treated by plasma jet and dielectric barrier discharge, Journal of Adhesion Science and Technology, 30:2, 218-229, DOI: 10.1080/01694243.2015.1099863

To link to this article: https://doi.org/10.1080/01694243.2015.1099863

\section{Published online: 16 Oct 2015.}

\section{Submit your article to this journal ¿}

Џ Article views: 182

View Crossmark data \lceil

Citing articles: 6 View citing articles $\square$ 


\title{
Polyurethane paint adhesion improvement on aluminium alloy treated by plasma jet and dielectric barrier discharge
}

\author{
T.S.M. Muia , L.L.G. Silva ${ }^{\mathrm{a}, \mathrm{b}}$, V. Prysiazhnyi and K.G. Kostov ${ }^{\mathrm{a}}$ \\ ${ }^{a}$ Faculty of Engineering - FEG, Universidade Estadual Paulista - UNESP, Guaratinguetá, Brazil; ${ }^{\text {}}$ Technological \\ Faculty of Pindamonhangaba - FATEC, Pindamonhangaba, Brazil
}

\begin{abstract}
The effect of atmospheric pressure plasma treatment on the adhesion between a protective coating and AA1100 alloy was investigated. Two plasma sources were used for surface modifications: atmospheric pressure plasma jet and dielectric barrier discharge. The surface roughness and water contact angle measurements were conducted in order to evaluate the changes on the aluminium surface after plasma processing. The paint coating was tested using the adhesion tape test (ASTM D3359). A significant improvement of surface wettability and adhesion was obtained after plasma treatments.
\end{abstract}

\section{ARTICLE HISTORY}

Received 31 March 2015

Revised 17 September 2015

Accepted 18 September 2015

\section{KEYWORDS}

Aluminium alloy; DBD; APPJ; adhesion tape test; surface treatment

\section{Introduction}

Aluminium (Al) alloys are widely employed in many industries. In the most applications, initial surface processing is required, as for example, pre-cleaning or activation. The chemical pre-treatments, which are frequently used for those purposes, are not environmentally friendly due to the production of hazardous by-products. In opposite, atmospheric pressure plasma treatment can be an alternative technology for initial surface processing. Nowadays, two major discharge systems have been investigated: atmospheric pressure plasma jet (APPJ) and dielectric barrier discharge (DBD). [1-5]

Atmospheric pressure plasma offers an attractive perspective in industrial processes due to the elimination of expensive vacuum equipment, allowing easy scaling and in-line processing and reduction of capital cost.[6] Plasma jets are kind of devices where plasma, produced by electrical discharge, extends beyond the generation region into the surrounding ambient by a gas flow and/or an electric filed. APPJs are usually generated in inert gases using different excitation mechanisms (DC and kilohertz frequency pulsed jets, sinusoidal jets, radio frequency RF jets and microwave excited jets).[7,8] APPJ has attracted much attention over the last decades, since it can be generated in open space and has the ability to produce reactive species at room temperature. Another advantage of plasma jets is that, differently from others plasma processes, in which samples are placed inside the reactors gap, the plasma jet treatments are not limited to flat and thin samples but can be also applied 
for treatment of 3D samples with complex geometry.[7] APPJs have been employed for materials processing,[9-11] sterilization, biological and medical purposes.[12,13]

DBD also known as 'silent discharge' is one of the most popular discharges used to generate cold non-equilibrium plasma at atmospheric pressure.[14] Originally, DBD was only used for ozone generation, however, during the years additional applications have been developed, such as excitation of $\mathrm{CO}_{2}$ lasers, excimer lamps, flat plasma displays, pollution control, sterilization and surface treatment (modification, cleaning, etching).[15-18]

When plasmas are in contact with surfaces depending on process parameters like energy input, pressure, working gas composition, as well as the nature of the substrate, a variety of chemical and physical processes can take place.[19] The most important of them are etching, thin film deposition, cleaning, activation of the surface and so on. Many materials, in particular polymers, are chemically inert and cannot bond easily to other materials, displaying poor adhesion with inks, paint and glues. The reason for this is the absence of polar and reactive functional groups in their structure. Plasma activation makes the surface more receptive to bonding with other substances by removing weak boundary layers (oxides, amorphous structures, etc.), cross-linking of surface molecules and by creating new polar functional groups.[20]

There are some investigations about the use of different types of plasma for aluminium alloys surface treatment. The authors [21,22] reported the effects of the corona discharge on an $\mathrm{Al}$ alloy. The eletrochemical tests showed a significant reduction in anodic and cathodic reactivities with the formation of a thicker $\mathrm{Al}$ oxide film. In [23], the authors presented the results of surface modification of an $\mathrm{Al}$ alloy by a low-pressure plasma treatment with and without the use of traditional chemical process with methyl ethyl ketone (MEK). At long treatment time, the plasma processing exhibited significant increase of $\mathrm{Al}$ alloy wettability and better surface cleaning, which is even better than the results obtained from the traditional treatment with MEK.

The use of atmospheric plasma for surface modification is well known, especially for polymers. However, there are only few investigations about DBD or plasma jet treatments on the metal surface.[24-27] Also, it has not been reported yet the use of DBD and plasma jet treatments on the aluminium alloy surface to enhance the adhesion of a polyurethane coating.

In this article, open nozzle APPJ and DBD systems were used to treat the aluminium alloy AA1100. The purpose of this work was to elucidate which treatment is more efficient to activate the $\mathrm{Al}$ surface and to enhance the adhesion of a polyurethane protective coating.

\section{Experimental}

\subsection{Materials}

The material used in this work was aluminium alloy AA1 $100(99 \% \mathrm{Al})$ whose dimensions were $25 \mathrm{~mm} \times 25 \mathrm{~mm} \times 0.3 \mathrm{~mm}$. The as-received samples without any previous surface preparation were pre-cleaned in ultrasonic bath by isopropanol and stored in air for at least $24 \mathrm{~h}$ prior any measurements or plasma treatments. The samples were not polished for enhancing the mechanic anchorage between the Al surface and paint coating. The reproducibility of the experiments was verified by performing each treatment on at least three samples. 


\subsection{Atmospheric pressure plasma jet}

A plasma jet terminating with a wide (horn-like) nozzle was used to treat the $\mathrm{Al}$ samples. The use of such nozzle has not been reported before. The jet system consisted of Pyrex tube with wide nozzle $(\varnothing=21 \mathrm{~mm})$, high-voltage electrode $(0.3 \mathrm{~mm}$ thick $\mathrm{Ni}-\mathrm{Cr})$ placed inside the tube and a glass table $(2.3 \mathrm{~mm}$ thick) with a grounded electrode $(\varnothing=155 \mathrm{~mm}$; thickness $=5 \mathrm{~mm}$ ) beneath it. The glass barrier was placed to prevent arc transition, while the grounded metal electrode was used to measure the discharge electric parameters.

Plasma was generated with an AC power supply (Minipuls 4, GBS Elektronik, Dresden, Germany) operating at $19 \mathrm{kHz}$ and applied voltages of $8 \mathrm{kVp}-\mathrm{p}$ and $12 \mathrm{kVp}-\mathrm{p}$. Dissipated power was calculated using Lissajous figure (a charge $\mathrm{x}$ voltage plot) technique,[14] with the corresponded values of $4.0 \pm 0.1 \mathrm{~W}$ and $9.7 \pm 0.2 \mathrm{~W}$. The device was flushed with argon flow of $1.2 \mathrm{~L} / \mathrm{min}$. For the given operation conditions, the plasma appeared as randomly distributed filaments between the high-voltage electrode and the Al substrate. The filaments were confined within the area of the jet's nozzle. Samples were exposed to plasma for $40 \mathrm{~s}$ using a nozzle-to-sample distance of $1 \mathrm{~mm}$. Energy per square unit transferred from the APPJ to the Al substrate was 44 and $108 \mathrm{~J} / \mathrm{cm}^{2}$, respectively, and it was calculated by multiplying the time of treatment to the total power, and dividing the product by the area of the jet nozzle. The image of plasma jet and the experimental configuration used in this work are shown in Figure 1.

\subsection{Dielectric barrier discharge}

The DBD reactor was a double barrier parallel plate volume DBD. The discharge was generated between two 9.5-cm-diameter parallel aluminium electrodes. The upper electrode was grounded and the lower one served as high-voltage electrode. Both electrodes were covered by a Mylar sheet with $0.5 \mathrm{~mm}$ thickness. Plasma was generated by an AC power supply $(60 \mathrm{~Hz})$ in airflow $(8 \mathrm{~L} / \mathrm{min})$. The inter-electrode gap was fixed to $1 \mathrm{~mm}$ and the applied voltage used was $20 \mathrm{kVp}-\mathrm{p}$ and $30 \mathrm{kVp}$-p, with plasmas powers of $0.6 \pm 0.1$ and $1.2 \pm 0.1 \mathrm{~W}$, respectively. Samples were exposed to air-DBD plasma for 18 and $44 \mathrm{~min}$ at $20 \mathrm{kV}$, and 6.5 and $16 \mathrm{~min}$ at $30 \mathrm{kV}$. The time was chosen to get the same values of energy per area $\left(44\right.$ and $108 \mathrm{~J} / \mathrm{cm}^{2}$ ) as in the APPJ treatment in order to compare both processes. In the case of $\mathrm{DBD}$, the energy density was calculated by multiplying the time of treatment to the total power, and dividing the product by the sample area. Since $\mathrm{Al}$ is a conductive sample, the plasma filaments were preferentially formed over the substrate surface and no plasma was observed outside the sample. The image of DBD reactor with a picture of the plasma inside it and schematic diagram of the experimental configuration are shown in Figure 2.

\subsection{Contact angle and surface free energy}

Contact angle and surface free energy (SFE) measurements were performed no more than 10 min after both plasma treatments on a Rame-Hart 300 goniometer, using the sessile drop method and the DropImage software. Deionized water and diiodomethane were used as test liquid and the volume of the droplets was $2 \mu \mathrm{l}$. The polar and dispersive components of SFE were obtained by geometric mean method. 


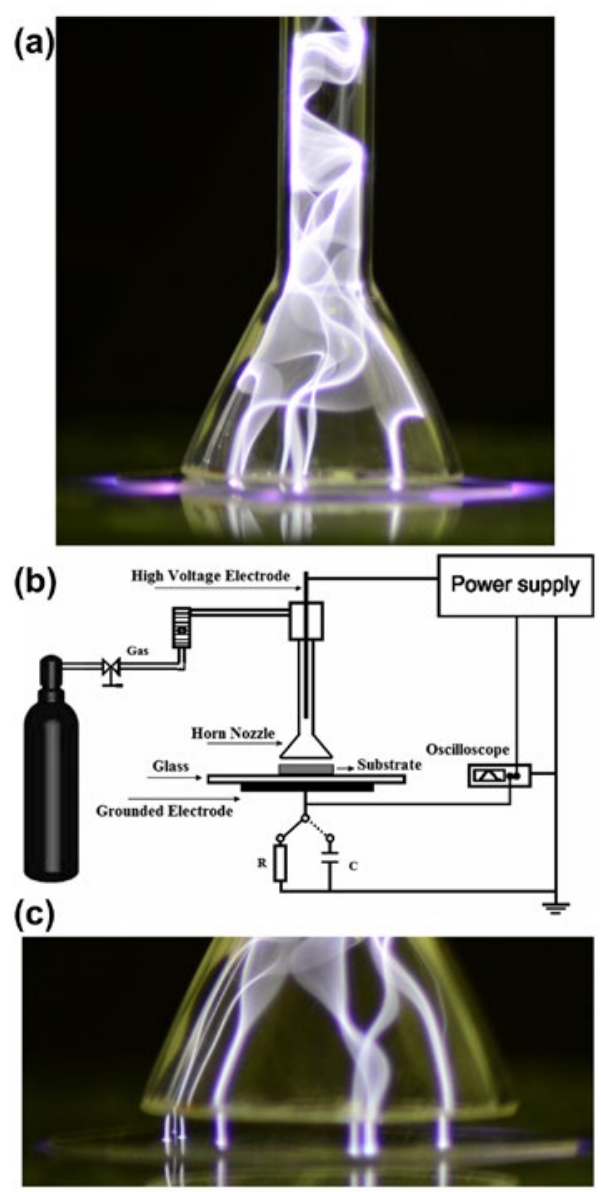

Figure 1. (a) APPJ image, (b) experimental set-up and (c) magnified plasma zone.

\subsection{Roughness measurements}

A Leica DCM 3D confocal microscope was used to assess the surface roughness. The sample topography was measured using $5 \mathrm{x}$ magnification objective with field of view $2.55 \times 1.91 \mathrm{~mm}$. The surface roughness $\left(R_{\mathrm{rms}}\right)$ value was obtained from a backgroundsubtracted surface topography using software provided by the manufacturer. Roughness profiles were extracted by oblique lines from the images of surface topography and a filter with 0.8 -mm cut-off was applied.

\subsection{Painting}

After plasma treatment, all samples were painted with polyurethane paint JET GLO ${ }^{\circledR}$ (Sherwin-Williams). The painting was applied with a small brush and performed no more than $10 \mathrm{~min}$ after the treatments. Samples were dried in room temperature for $48 \mathrm{~h}$. 

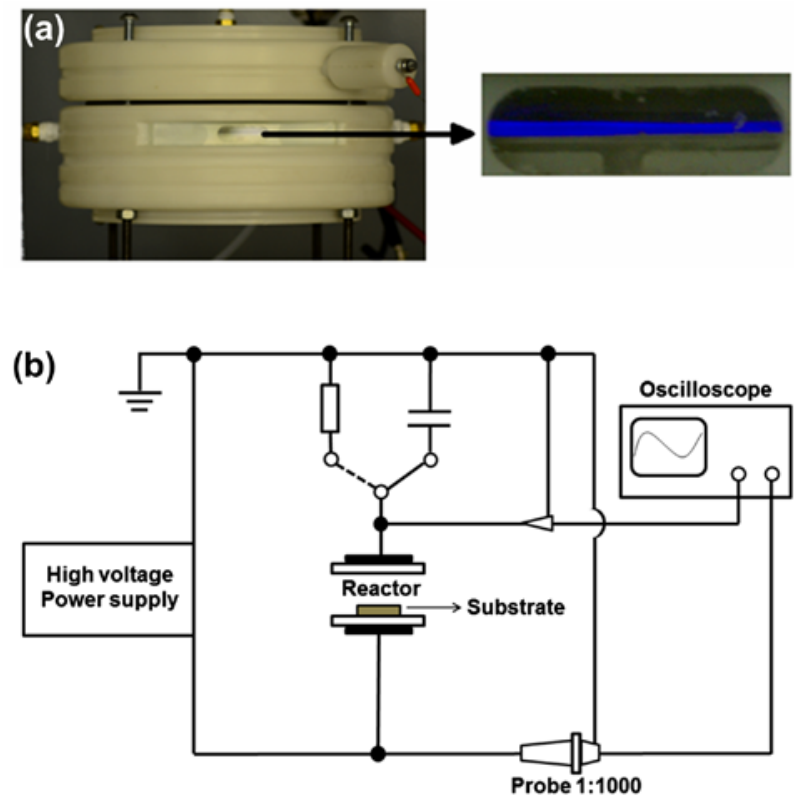

Figure 2. (a) Image of DBD reactor with an inset showing the discharge and (b) experimental set-up.

\subsection{Adhesion tape test}

The adhesion tape test is commonly used to assess the adhesion of a paint or coating to a metallic or plastic substrate, by applying and removing pressure-sensitive tape over cuts made on the paint through the substrate.[28]

In this investigation, the adhesion tape test was performed in according to Method B Test in ASTM D3359.[29] Incisions were made on the painted Al surface in horizontal and vertical directions (these lines form 25 squares with $2 \mathrm{~mm}$ side). Afterwards, the tape was placed over the grid formed by the cuts. To ensure good contact, an eraser was used to rub the tape on the substrate. The tape was applied for $90 \mathrm{~s}$ and then removed. The classification of the adhesion was made by comparison with the adhesion test table results available in ASTM D3359.

\section{Results and discussion}

\subsection{Contact angle and SFE}

The water contact angle (WCA) was affected by both atmospheric pressure plasma processes, as shown in Figure 3. WCA of Al surface decreased from $87^{\circ}$ (the value for untreated sample) down to $8^{\circ}$ and $13^{\circ}$ after APPJ and DBD treatments, respectively. The same behaviour was observed for the diiodomethane contact angle, where a decrease from $65^{\circ}$ (the value for untreated $\mathrm{Al}$ surface) up to $34^{\circ}$ after both treatments was obtained.

Figure 4 shows a bar plot of WCA of Al surface after the different plasma processes. As can be seen, when the energy dose is increased (by increasing the time of treatment or the 


\section{(a)}

\section{Contact Angle: $8^{\circ}$}

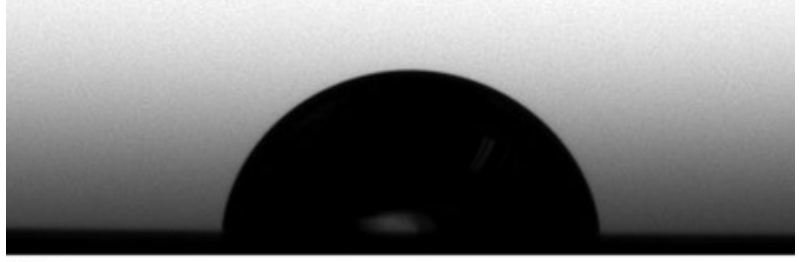

(b)

Contact Angle: 6

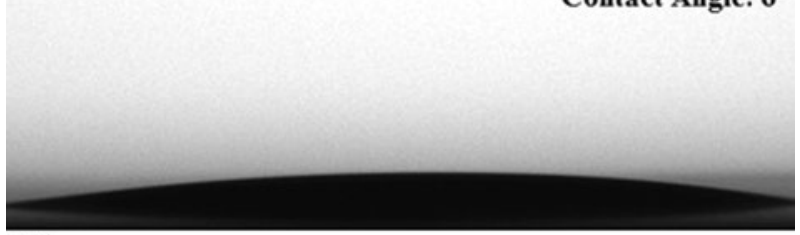

(c)

Contact Angle: $13^{\circ}$

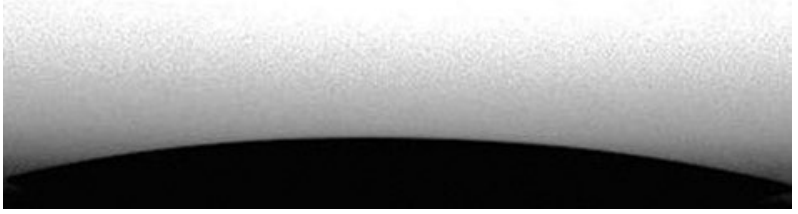

Figure 3. Images of water droplets on (a) untreated sample, (b) DBD (30 kV, 16 min) treated sample and (c) APPJ (12 kV, 40 s) treated sample.

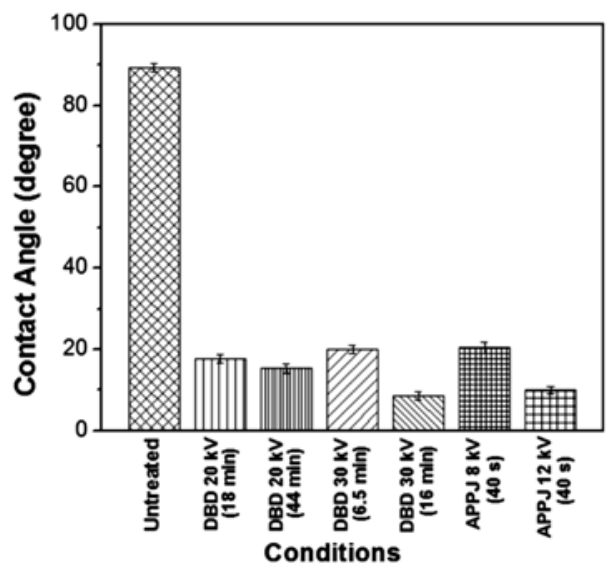

Figure 4. WCAs for treated and untreated Al samples.

applied voltage), the WCA tends to decrease for both processes. The best wettablity was obtained for the DBD process at $30 \mathrm{kV}, 16$ min and for the APPJ at $12 \mathrm{kV}, 40 \mathrm{~s}$.

SFE values after plasma treatments were visibly different when compared to the untreated sample, as presented in Figure 5. An increase of the SFE from $33 \mathrm{mN} / \mathrm{m}^{2}$ (untreated Al surface) to up to $75 \mathrm{mN} / \mathrm{m}^{2}$ (after plasma treatments) was observed. Both components of 


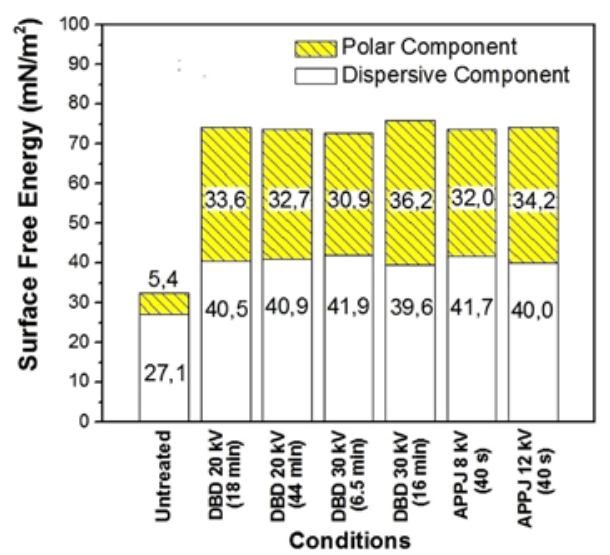

Figure 5. SFE measurements for the untreated and treated Al samples.

SFE, the dispersive and the polar one, increased after the plasma treatment. However, it can be noted a substantial enhancement of the polar component of the SFE. This can be related to the incorporation of polar groups on the Al surface. In [24], the authors inferred that the SFE increased mainly due to the rise of its polar component. It was caused by the formation of polar groups $\left(-\mathrm{NH}-,-\mathrm{NO}_{2},-\mathrm{NO}_{3}\right)$ on the $\mathrm{Al}$ surface as a consequence of the plasma exposure.

The values of SFE are approximately the same for all treated samples. Although, it can be observed from Figures 4 and 5 that the condition at which the lowest WCA and the highest SFE was obtained was the DBD-treated sample at $30 \mathrm{kV}(16 \mathrm{~min})$. The increase in SFE values promotes an improvement of surface wettability. Therefore, surface modifications using both plasma systems led to a super-hydrophilic surface, which should result to a better adhesion of paint on the Al substrate.

The values of contact angle and SFE obtained in this experiment are in agreement with previous works, $[25,26]$ where different kinds of plasma and experimental parameters were employed to treat different $\mathrm{Al}$ alloys.

\subsection{Roughness measurements}

The mean free path of plasma particles in atmospheric pressure discharges is very small so that the plasma species have very low kinetic energy. Therefore, the surface modification by sputtering is not possible at atmospheric pressure. In case of reactive gases, however, some material can be removed from the sample surface by etching. However, in air environment, this is also a very mild process. For example in [27], the authors obtained a slightly higher roughness after treating $\mathrm{Al}$ alloys with plasma.

Figure 6 presents the 3D images of untreated and treated samples. The roughness values obtained from 3D images (Figure 6) and are listed in Table 1.

It can be concluded from the Table 1 that within the experimental uncertainty, the roughness of as-received and the treated samples is practically the same. Thus, both atmospheric plasma treatments introduced insignificant changes in the surface roughness, which means that the improved wettability in the experiments was not caused by surface roughening. 

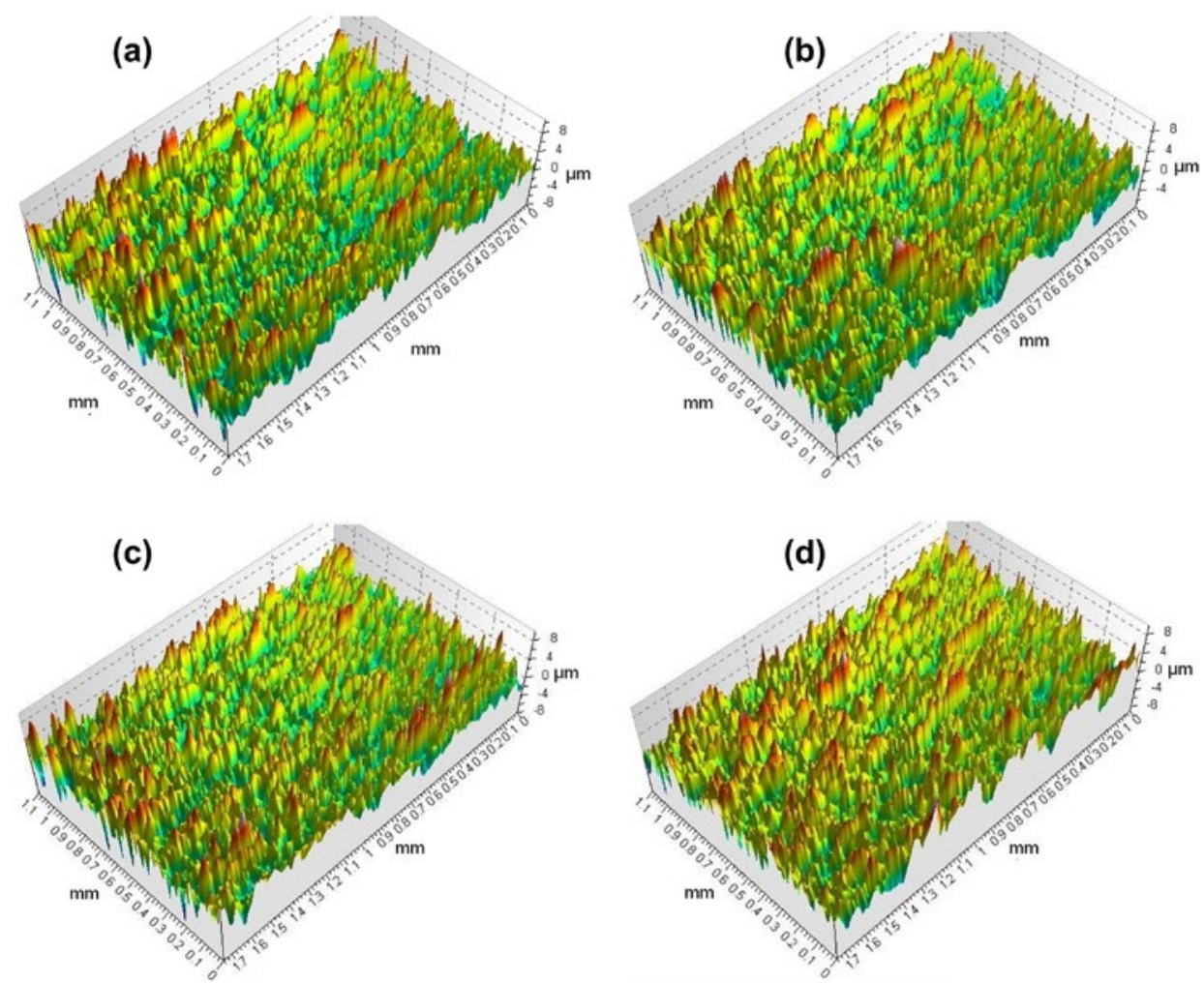

Figure 6. AA1100 alloy surface morphology (3D images) for the conditions: (a) untreated, (b) APPJ $12 \mathrm{kV}$, $40 \mathrm{~s}$ (c) DBD $20 \mathrm{kV}, 44$ min and (d) DBD $30 \mathrm{kV}, 16$ min.

Table 1. The roughness values for untreated and treated Al alloys.

\begin{tabular}{lcc}
\hline Condition & $R_{\mathrm{rms}}(\mu \mathrm{m})$ & Standard deviation $( \pm \mu \mathrm{m})$ \\
\hline Untreated & 1.71 & 0.20 \\
APPJ & 1.55 & 0.32 \\
DBD & 1.83 & 0.21 \\
\hline
\end{tabular}

Therefore, the increased hydrophilicity after the plasma processing is probably due to surface activation and incorporation of oxygen and nitrogen species on the $\mathrm{Al}$ surface, which is in an agreement with the significant increase of SFE polar component.

\subsection{Adhesion tape test}

Figure 7 shows the adhesion tape test results on painted untreated sample, in which the paint inside the grid came off completely after the tape test was applied to the untreated sample.

The same tape test procedure was performed on samples exposed to plasma. Figure 8 presents the adhesion tape test results for samples treated by APPJ and DBD.

Figure $8(\mathrm{a})$, (b) represent the samples treated with APPJ at 8 and $12 \mathrm{kV}$, respectively. Both conditions resulted in perfect adhesion, since no paint was removed inside the grid. Note that there was paint detachment only on the areas that were outside the jet nozzle (not exposed to the plasma). 

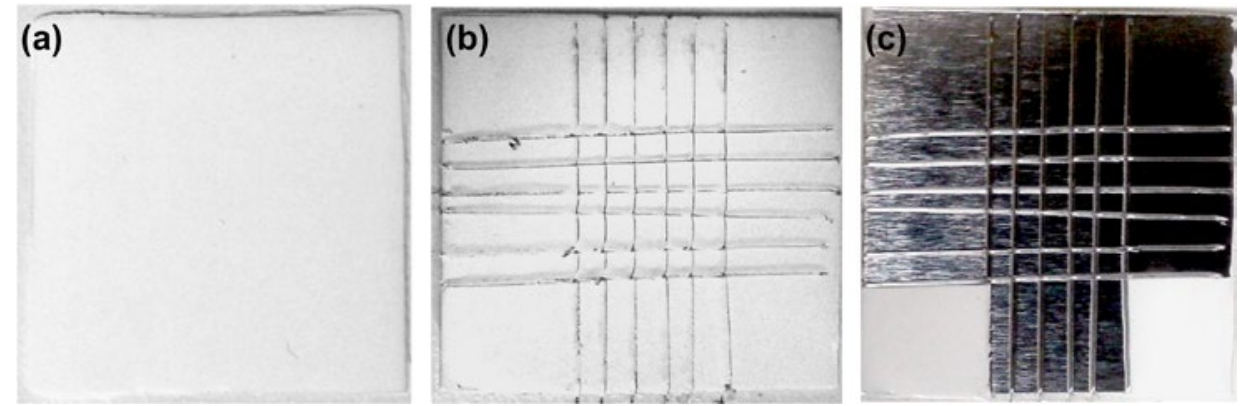

Figure 7. Painted untreated AA1100 sample (a) painted sample, (b) cross-cut area and (c) result after adhesion tape test.
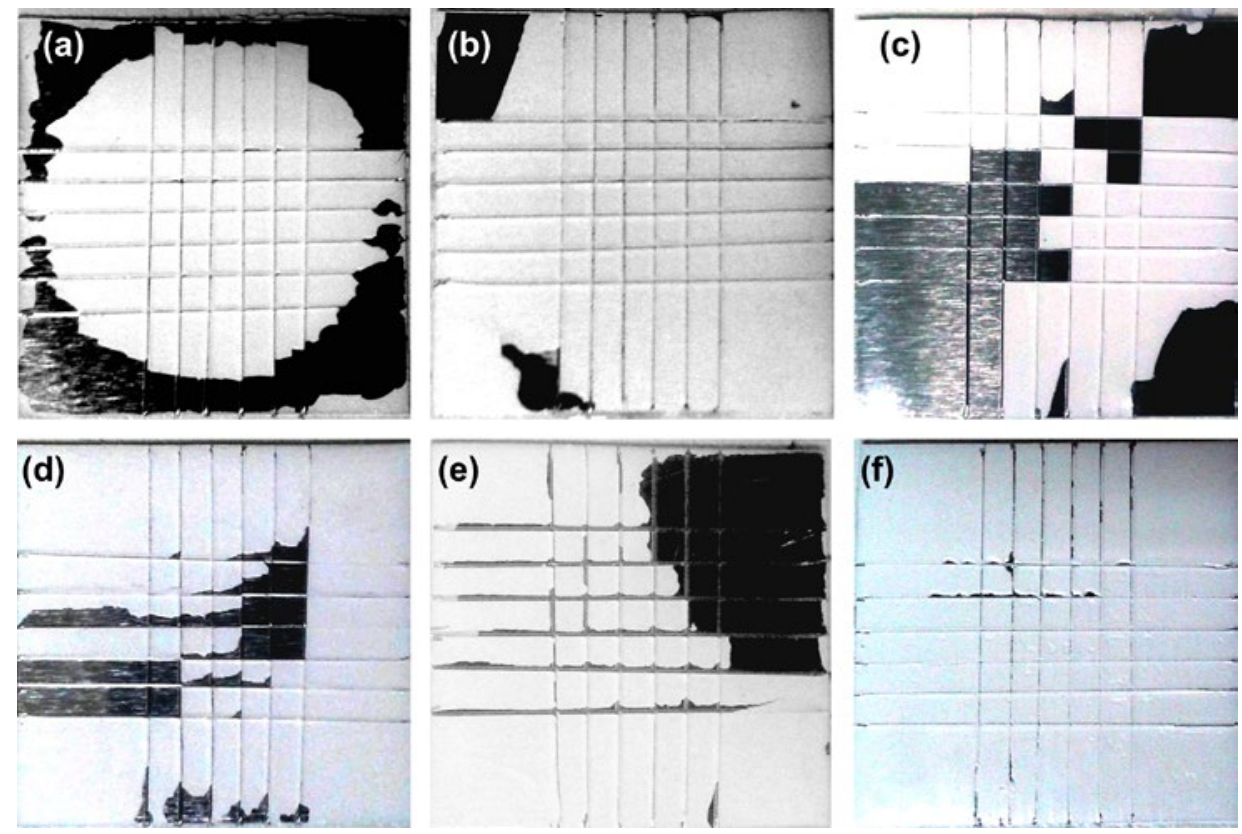

Figure 8. Adhesion tape test results for the conditions: (a) APPJ 8 kV, 40 s, (b) APPJ 12 kV, 40 s, (c) DBD $20 \mathrm{kV}, 18 \mathrm{~min}$, (d) DBD 20 kV, 44 min, (e) DBD 30 kV, 6.5 min and (f) DBD 30 kV, 16 min.

Differently, the DBD-treated samples at $20 \mathrm{kV}$ and $18 \mathrm{~min}$ (Figure 8(c)) showed that about $50 \%$ of the paint was removed outside and inside the grid. While for the DBD process at $20 \mathrm{kV}$ and $44 \mathrm{~min}$ (Figure $8(\mathrm{~d})$ ), the sample presented more than $35 \%$ paint removal inside the grid. In addition, for DBD-treated sample at $30 \mathrm{kV}$ and $6.5 \mathrm{~min}$ (Figure 8(e)) about $20 \%$ of the paint was removed from the grid. For the last condition, DBD-treated sample at $30 \mathrm{kV}$ and $16 \mathrm{~min}$ (Figure $8(\mathrm{f})$ ) showed a slight paint removal inside the grid corresponding to less than $5 \%$.

According to ASTM D3359, the results of adhesion tape test must be classified in a scale from $0 \mathrm{~B}$ to $5 \mathrm{~B}$. This scale is based upon the percentage of the removed coating area inside 
Table 2. Classification of adhesion tape test results according to ASTM D3359.

\begin{tabular}{lccc}
\hline Figure & Condition & Classification & Percentage of area removed (\%) \\
\hline Figure 7 & Untreated & $0 B$ & more than 65 \\
Figure 8(a) & APPJ (8 kV-40 s) & $5 B$ & none \\
Figure 8(b) 8b & APPJ (12 kV-40 s) & $5 B$ & none \\
Figure 8(c) 8c & DBD (20 kV-18 min) & $1 \mathrm{~B}$ & $35-65$ \\
Figure 8(d) & DBD (20 kV-44 min) & $1 \mathrm{~B}$ & $35-65$ \\
Figure 8) & DBD (30 kV-6.5 min) & $2 \mathrm{~B}$ & $15-35$ \\
Figure 8(f) 8f & DBD (30 kV-16 min) & $4 \mathrm{~B}$ & Less than 5 \\
\hline
\end{tabular}

the grid after the test. The classification of the results obtained by comparison is presented in Table 2.

Both plasma treatments improved the adhesion of the polyurethane paint to the AA1100 alloy, when compared to the untreated sample. However, the treatments that presented the best adhesion test results were the APPJ ( 8 and $12 \mathrm{kV})$ and after that the DBD treatment at $30 \mathrm{kV}$ and $16 \mathrm{~min}$. Even when both plasma treatments were with a different energy per square unit (APPJ - $44 \mathrm{~J} / \mathrm{cm}^{2}$ and DBD - $108 \mathrm{~J} / \mathrm{cm}^{2}$ ) still the APPJ process was more efficient in improving the paint adhesion to $\mathrm{Al}$ substrate. This finding needs further investigation, however, a possible explanation is a different composition of APPJ and DBD plasmas. In fact, the active species in DBD plasma are generated by electron impact [2] while the dominant mechanism in APPJs for producing $\mathrm{O}$ and $\mathrm{N}$ moieties are three body reactions with Ar metastable.[8]

In literature,[30] the adhesion tape test performed by the authors showed that the low-pressure plasma treatment alone was not sufficient to obtain 100\% paint adhesion. This condition was only achieved using the following processes sequence: plasma treatment, primer application on the $\mathrm{Al}$ surface and after that the paint layer application. In our investigation, the plasma jet treatment alone led to perfect adhesion of the polyurethane paint on the Al substrate without assistance of a primer layer. Therefore, the results obtained with atmospheric pressure plasma can be considered promising since there is no need of an extra primer layer to get perfect paint adhesion. Moreover, when both plasmas process are compared, the atmospheric pressure plasma has advantage because neither vacuum chambers nor pumps are required.

It is often difficult to ascribe adhesive bonding to an individual mechanism. A combination of different mechanisms is usually responsible for bonding in a given adhesive system. The extent of the role of each mechanism would then vary for different systems.[31] The improvement obtained in the adhesion of the polyurethane painting can be attributed to the incorporation of polar groups into the Al surface, evidenced by the increase of the polar component in the SFE. Since, it was verified that the adhesion was not caused by mechanical interlocking or roughening, the wetting theory [32] can be applied in this case. Therefore, one can conclude that in this work the adhesion improvement can be attributed to the increased wetting of the $\mathrm{Al}$ surface after plasma treatments.

\section{Conclusion}

AA1100 alloy was treated with two commonly used atmospheric pressure plasma sources, APPJ and DBD. The effect of plasma on surface wettability, roughness and adhesion of polyurethane paint were investigated. 
(1) The contact angle decreased from $87^{\circ}$ (nearly hydrophobic) down to $8^{\circ}$ and $13^{\circ}$ after APPJ and DBD treatments, respectively.

(2) The plasma exposure did not induce significant changes in topography and surface roughness. Thus, the main effect of the plasma is in surface activation and cleaning.

(3) With the adhesion tape test was possible to verify that both conditions of APPJ $(8 \mathrm{kV}$ and $12 \mathrm{kV})$ and the DBD $30 \mathrm{kV}(16 \mathrm{~min})$ improved significantly the adhesion of the polyurethane paint to the aluminium substrate. Both plasma systems (APPJ and DBD) were efficient to modify the AA1100 surface by increasing its wettability. However, according to results obtained by the adhesion tape test, the APPJ system was more efficient than the $\mathrm{DBD}$ in improving the adhesion of the polyurethane coating to the $\mathrm{Al}$ substrate at the investigated conditions.

\section{Disclosure statement}

No potential conflict of interest was reported by the authors.

\section{References}

[1] Bárdos L, Baránková H. Cold atmospheric plasma: sources, processes, and applications. Thin Solid Films. 2010;518:6705-6713.

[2] Tendero C, Tixier C, Tristant P, et al. Atmospheric pressure plasmas: a review. Spectrochim. Acta, Part B. 2006;61:2-30.

[3] Prysiazhnyi V, Svoboda T, Dvořák M, et al. Aluminum surface treatment by the RF plasma pencil Surf. Coat. Technol. 2012;206:4140-4145.

[4] Kostov KG, Nishime TCM, Hein LRO, et al. Study of polypropylene surface modification by air dielectric barrier discharge operated at two different frequencies. Surf. Coat. Technol. 2013;234:60-66.

[5] Ritz E, Wu YL, Hong J, et al. Atmospheric pressure dielectric barrier discharge (DBD) for post-annealing of aluminum doped zinc oxide (AZO) films. Surf. Coat. Technol. 2014;251: 64-68.

[6] Deynse AV, Cools P, Leys C, et al. Surface activation of polyethylene with an argon atmospheric pressure plasma jet: influence of applied power and flow rate. Appl. Surf. Sci. 2015;328:269-278.

[7] Walsh JL, Iza F, Janson NB, et al. Three distinct modes in a cold atmospheric pressure plasma jet. J. Phys. D: Appl. Phys. 2010;43:075201.

[8] Lu X, Laroussi M, Puech V. On atmospheric-pressure non-equilibrium plasma jets and plasma bullets. Plasma Sources Sci. Technol. 2012;21:034005.

[9] Pavliňák D, Hnilica J, Quade A, et al. Functionalisation and pore size control of electrospun PA6 nanofibres using a microwave jet plasma. Polym. Degrad. Stab. 2014;108:48-55.

[10] Noeske M, Degenhardt J, Strudthoff S, et al. Plasma jet treatment of five polymers at atmospheric pressure: surface modifications and the relevance for adhesion. Int. J. Adhes. Adhes. 2004;24:171-177.

[11] Sainz-García E, Alba-Elías F, Múgica-Vidal R, et al. Enhanced surface friction coefficient and hydrophobicity of TPE substrates using an APPJ system. Appl. Surf. Sci. 2015;328:554-567.

[12] Keidar M, Shashurin A, Volotskova O, et al. Cold atmospheric plasma in cancer therapy. Phys. Plasmas. 2013;20:057101.

[13] Park GY, Park SJ, Choi MY, et al. Atmospheric-pressure plasma sources for biomedical applications. Plasma Sources Sci. Technol. 2012;21:043001.

[14] Kogelschatz U. Dielectric-barrier discharges: their history, discharge physics, and industrial applications. Plasma Chem. Plasma Process. 2003; 23:1-46.

[15] Bellebna Y, Tilmatine A. Application of dielectric surface barrier discharge for air disinfection. Acta Electrotech. Inform. 2013;13:22. 
[16] Oravcova A, Hudec I. The influence of atmospheric pressure plasma treatment on surface properties of polypropylene films. Acta Chim. Slovaca. 2010;3:57-62.

[17] Shao T, Zhang C, Long K, et al. Surface modification of polyimide films using unipolar nanosecond-pulse DBD in atmospheric air. Appl. Surf. Sci. 2010;256:3888-3894.

[18] Kostov KG, dos Santos ALR, Honda RY, et al. Treatment of PET and PU polymers by atmospheric pressure plasma generated in dielectric barrier discharge in air. Surf. Coat. Technol. 2010;204:3064-3068.

[19] Woedtke TV, Reuter S, Masur K, et al. Plasmas for medicine. Phys. Rep. 2013;530:291-320.

[20] Federal Ministry of Education and Research. Plasma technology. Process Diversity + Sustainability. Bonn: MBBF PUBLIC; 2001.

[21] Minzari D, Møller P, Kingshott P, et al. Surface oxide formation during corona discharge treatment of AA 1050 aluminium surfaces. Corros. Sci. 2008;50:1321-1330.

[22] Jariyaboon M, Møller P, Dunin-Borkowski RE, et al. The effect of atmospheric corona treatment on AA1050 aluminium. Corros. Sci. 2012;52:2155-2163.

[23] Sorrentino L, Carrino L. 2024 aluminium alloy wettability and superficial cleaning improvement by air cold plasma treatment. J. Mater. Process. Technol. 2009;209:1400-1409.

[24] Brunelli K, Pezzato L, Napolitani E, et al. Effects of atmospheric pressure plasma JET treatment on aluminium alloys. Surf. Eng. 2014;30.

[25] Saleema N, Gallant D. Atmospheric pressure plasma oxidation of AA6061-T6 aluminum alloy surface for strong and durable adhesive bonding applications. Appl. Surf. Sci. 2013;282:98-104.

[26] Bónová L, Zahoranová A, Kováčik D, et al. Atmospheric pressure plasma treatment of flat aluminum surface. Appl. Surf. Sci. 2015;331:79-86.

[27] Bónová L, Buček A, Plecenik T, et al. Cleaning of aluminium surface using diffuse coplanar surface barrier discharge. Chem. Listy. 2008;102:s1452-s1454.

[28] $\mathrm{Ku} \mathrm{JH}$, Jung IH, Rhee KY, et al. Atmospheric pressure plasma treatment of polypropylene to improve the bonding strength of polypropylene/aluminum composites. Composites Part B: Eng. 2013;45:1282-1287.

[29] ASTM D3359-09. Standard test methods for measuring adhesion by tape test, doi:10.1520/ D3359-09.

[30] Polini W, Sorrentino L. Adhesion of a protective coating on a surface of aluminium alloy treated by air cold plasma. Int. J. Adhes. Adhes. 2007;27:1-8.

[31] Ebnesajjad S, Ebnesajjad C. Surface treatment of materials for adhesive bonding. 2nd ed. Elsevier: William Andrew; 2014.

[32] Ebnesajjad S, Landrock H. Adhesive technology handbook. 2nd ed. Norwich (NY): William Andrew; 2008. 